\title{
Distance Learning in Indonesia: How Are Our Teachers Doing?
}

\author{
Jovita Antonia Unggara ${ }^{1 *}$ Monika Monika ${ }^{1}$ \\ ${ }^{1}$ Faculty of Psychology, Universitas Tarumanagara, West Jakarta 11440, DKI Jakarta, Indonesia \\ "Corresponding author. Email: monika@fpsi.untar.ac.id
}

\begin{abstract}
Currently, education is one of the national sectors that are influenced by the pandemic. In that case, teachers are one of those parties who are affected by the changes. The purpose of this research is to examine the relationship between teacher stress and psychological well-being in junior high school teachers in context of distance learning practice. As a teacher, a person is responsible for their role to advance the national education system. Teachers' workloads are increasing, especially in this pandemic situation that requires distance learning. Heavy workloads as well as the pressure to keep doing their best in teaching can trigger teacher stress, which will impact their psychological well-being. Teacher stress is a negative emotional state experienced by individuals that is caused by events related to their role as a teacher. In the other hand, psychological well-being is a state achieved by individuals when they can function effectively as an person and capable of doing improvements to fully develop their potentials. This research involved 147 junior high school teachers in Indonesia that consisted of 60 male teachers and 87 female teachers. Measures used in this research are translated version of Teacher Stress Measures and Ryff's Psychological Well-being Scale that have been adapted to be relevant to the distance learning conditions. Analysis using Spearman correlation technique shows $r(147)=-0.688$ and $p=0.000<0.05$. This shows that both variables have a significant and negative correlation. Thus, it can be concluded that higher levels of teacher stress leads to low psychological well-being in teachers.
\end{abstract}

Keywords: Teacher stress, psychological well-being, and distance learning

\section{INTRODUCTION}

In Indonesia, education is an important factor that contributes to the quality of national human resources. Yet, because of the pandemic situation, the learning system has to change from traditional learning system to distance learning system which requires technology and different class management skills. Many are affected by these changes and teachers are one of them. There are two main concerns related to teachers and distance learning. Limited internet access for teachers in some regions in Indonesia and teachers' incapability of using technologies that helps distance learning activities are the main obstruction to the learning process throughout this pandemic situation [1].

Generally, there are a lot of challenges faced by teachers in Indonesia. Especially, teachers in junior high school who have to facilitated their students go through transition from elementary school and other changes [2]. Changes in learning system and heavy workloads may cause stress in teachers and affect their psychological well-being $[3,4]$.

\subsection{Teacher Psychological Well-Being}

Well-being is not just a happy feeling. Furthermore, it has a broad meaning associated with personal and social values which each of individuals hold on to. Huppert [5] defines psychological well-being as a 'well' feeling that felt by individuals and their capabilities to manage their lives effectively. The term of psychological well-being comes from two perspectives, hedonia and eudaimonia [6]. Hedonia is related subjective well-being that relates to positive emotions and life satisfaction in general [7]. In the onther hand, eudaimonia is based on well-being theory initiated by Carol D. Ryff.

According to Ryff, psychological well-being is a state which attained by individuals related to their ability to maximally manage their functions as human beings [8]. Individuals with high level of psychological well-being tend to: (a) have a positive attitude toward themselves and their past, (b) have a harmonious and warm relationships with others, (c) be independent and persistent, (d) have the ability to control the circumstances, (e) have a clear life vision, and (f) have the will to grow as a person. Psychological well-being itself consists of six dimensions. There are self-acceptance, positive relations with others, 
autonomy, environmental mastery, purpose in life, and personal growth [9]. In the measurement, individuals with high level of psychological wellbeing show high scores in these dimensions and vice versa.

In learning context, teachers with high level of psychological well-being are able to show their best qualities and competencies throughout the learning process [10]. If the teachers are well, they are also able to develop and maintain harmonious relationship with their students and have an effective class management strategy [11]. Well teachers are able to contribute in learning process with their most creative and innovate way in order to create qualified students for the future [12].

\subsection{Teacher Stress}

Physically, Selye defines stress as a mental state or emotional tension experienced by individuals caused by their implications to some harmful situations [13]. Lazarus and Folkman describe stress as a transactional relationship between individuals and their surroundings. It can be positive or negative, depends on how individuals perceive the stimulus and how they act towards it [14]. Stimulus that cause stress in individuals are called stressors. Specifically, teacher stress is an unsatisfying condition experienced by individuals resulting from their job as a teacher [15]. In this case, stressors are the demands from the environment received by individuals regarding their job as a teacher.

Teacher stress is caused by several factors, some of them are task-based stress, role-related stress, and environmental stress [16]. Task-based stress comes from problems those were related to overwhelming amounts of school work that teachers had. Role-related stress is caused by conflicting ideas about teachers' own expectation about their job and the actual job condition. Lastly, environmental stress is linked to the situations in which individual experiences throughout their career journey as a teacher, e.g. school or class environment. These factors are measured by thirteen dimensions of teacher stress. There are (a) role ambiguity, (b) role overload, (c) role conflict, (d) nonparticipation, (e) role preparedness, (f) school stress, (g) job satisfaction, (h) management style, (i) life satisfaction, (j) task stress, (k) supervisory support, (l) peer support, dan (m) illness symptoms.

In learning context and situation, high level of teacher stress can affect teaching performance and the learning outcomes. Teachers with high level of stress will experience sleep problems and other health problems $[17,18]$. This can cause exhaustion and may leads to negative behavior towards students in class setting causing disturbed learning process and worsen teacher-student relationships [19].

\subsection{Our Contribution}

This paper presents some improvements on research about teachers, especially teachers in Indonesia. During this novel situation that requires changes in learning system, we must pay more attention to teachers. The results of this research can be used as a references for teachers and/or school to make a better system to reach a better teachers' condition dan learning outcomes.

\subsection{Paper Structure}

This paper consists of four sections. Section one introduces the phenomenon and base theories of this research. Section two describes about who were the participants of this research, what measurement are used, and how was the research procedure going on. Section three presents research findings and discussion. Lastly, section four describes the conclusion of this research study.

\section{METHODS}

\subsection{Participants}

Participants of this research consisted of 147 junior high school teachers from Indonesia that varies in demographic characteristics. Based on gender, 59.2\% participants were female teachers and the rest were male. Based on age groups, there were $24.5 \%$ participants ranging from age 20 to $29,38.8 \%$ were age 30 to $39,21.8 \%$ were 40 to 49 , and $15 \%$ were age 50 to 59 . Based on the school location, $50.3 \%$ of them were working in schools located in Jakarta. Based on the type of school, there were $65.3 \%$ participants who came from private school and $34.7 \%$ from public school.

Based on teaching experiences, the highest percentage was teachers who had two to six years of experience in teaching in the same school (48.3\%). Additionally, based on their monthly salary, only $40.8 \%$ of the participants had more than 5 million per month. The rest had between three to five million or even under 3 million per month. Based on participants' educational background, $85 \%$ of them said the subject they are currently teaching is similar to their educational background. This research also asked question about the availability of the training regarding the distance learning system. With that, $78.9 \%$ of the participants responded 'yes'.

\subsection{Measures}

\subsubsection{Teacher Stress}

In this research, teacher stress variable was measured using Teacher Stress Measures [20]. The measurement was then translated and adapted to fit the distance learning situation. This adapted measure consist of 62 items that varies along 13 dimensions of teacher stress. The item were rated on 5 point Likert scale with response options of "Strongly disagree", "Disagree", "Likely to disagree", "Somewhat agree", and "Agree" relating to participants' perceptions of their conditions as a teacher. An example item is "I can predict what's expected of me for my work 
tomorrow". The internal consistencies of this measure ranged from 0.653 to 0.927 (average is 0.888 ).

\subsubsection{Psychological Well-Being}

Teachers' psychological well-being were measured using Ryff. Psychological Well-being Scale [21]. The scale was then adapted to be relevant with the distance-learning conditions. Measure consists of 24 items those were rated on 5-point Likert scale with response options of "Strongly disagree", "Disagree", "Likely to disagree", "Somewhat agree", and "Agree" relating to participants' perceptions of their psychological well-being during this pandemic situation and distance learning system. An example item is "Throughout distance learning, I am able to create new teaching method that suits me well". The internal consistencies of this measure ranged from 0.613 to 0.843 (average is 0.855 ).

\subsection{Procedures}

The approval of all research procedures was given from the Faculty of Psychology, Universitas Tarumanagara, Jakarta. Teachers were contacted and asked if they are willing to fill in the research form that contains informed consent, personal data that contains demographic information, and variable measurements. Because of the current situation, researcher was not able to get the printed (hardcopy) version to each of the participants. However, all the research questions were then given to the teachers in a Google Form format. Participants were able to ask the researcher if they had any questions about the questionnaire throughout the researcher email and/or phone number.

After gathering all the data from Google Form sheets, we continued to process the data with Statistical Package for the Social Sciences (SPSS) which result is described in section three.

\section{FINDINGS AND DISCUSSIONS}

Table 1 Descriptive statistics of teacher stress dimensions

\begin{tabular}{ccccc}
\hline Dimensions & Minimum & Maximum & Means & SD \\
\hline Role Ambiguity & 1.00 & 3.60 & 1.8163 & 0.59519 \\
Role Overload & 1.00 & 4.60 & 2.5524 & 0.85089 \\
Role Conflict & 1.00 & 4.60 & 2.2789 & 0.85482 \\
Nonparticipation & 1.00 & 4.20 & 2.1932 & 0.72995 \\
Role Preparedness & 1.00 & 3.67 & 1.9184 & 0.63581 \\
School Stress & 1.00 & 5.00 & 2.5986 & 0.90070 \\
Job Satisfaction & 1.00 & 4.20 & 2.0762 & 0.64078 \\
Management Style & 1.00 & 3.80 & 1.9673 & 0.65083 \\
Life Satisfaction & 1.00 & 4.20 & 1.7714 & 0.68686 \\
Task Stress & 1.00 & 3.89 & 2.3711 & 0.94965 \\
Supervisory Support & 1.00 & 4.00 & 1.8503 & 0.73306 \\
Peer Support & 1.00 & 3.22 & 1.7506 & 0.61912 \\
Illness Symptoms & 1.00 & 5.00 & 2.0595 & 0.94377 \\
\hline
\end{tabular}

Table 1 presents the minimum and maximum values, means, and standard deviations for each dimension of teacher stress variable. The means are all under the measurement hypothetical mean (three), which means most of the participants in this research had a low level of teacher stress. However, it shows that some participants still score high on teacher stress as seen in the maximum values that reach the maximum scale (five). School stress dimension has the highest mean score and the lowest is peer support. It means that during this distance learning implementation, teacher experiences stress caused by their perception of their conditions in teaching setting. In the other hand, lower level of teacher stress is caused by the good quality of support system teachers got from their peers.

Table 2 Descriptive statistics of psychological well-being dimensions

\begin{tabular}{ccccc}
\hline Dimensions & Minimum & Maximum & Mean & SD \\
\hline Autonomy & 1.00 & 5.00 & 3.4467 & 0.92529 \\
Environmental Mastery & 1.00 & 5.00 & 3.7279 & 0.93767 \\
Personal Growth & 1.80 & 5.00 & 3.9769 & 0.70167 \\
Positive Relations with Others & 2.17 & 5.00 & 3.9909 & 0.65422 \\
Purpose in Life & 1.00 & 5.00 & 3.9637 & 0.83414 \\
Self-Acceptance & 1.00 & 5.00 & 3.4422 & 0.91342 \\
\hline
\end{tabular}


Table 2 shows the minimum and maximum values, means, and standard deviations for each dimension of psychological well-being variable. The means are all above the measurement hypothetical mean (three), which means most of the participants had a high level of psychological well-being. In the other hand, there's still some participants who score low in psychological wellbeing, as seen in the minimum values that reached the minimum scale (one). The dimension with the highest mean score is positive relations with others and the lowest is self-acceptance. This means high levels of psychological well-being is supported by teachers' ability to maintain a harmonious, warm and close relationships with other people. In the other hand, teachers with low score of psychological well-being is lack of positive feeling towards self and their past.

Table 3 Correlational analyses between variables

\begin{tabular}{cc}
\hline & Teacher Stress x Psychological Well-Being \\
\hline $\mathbf{r}$ & -0.688 \\
$\mathbf{p}$ & 0.000 \\
\hline
\end{tabular}

Table 3 shows the result from correlational analysis. In this research, Spearman's correlation technique was used. It shows that there is a significant and negative relation between teacher stress and psychological well-being $(r=-$ $.688 ; \mathrm{p}=.000<.05)$.

Table 4 Correlational analyses between teacher stress variable and PWB dimensions

\begin{tabular}{cccc}
\hline & & \multicolumn{2}{c}{ Teacher Stress Variable } \\
& & r & p \\
\hline \multicolumn{2}{c}{ Autonomy } & -0.471 & 0.000 \\
Environmental Mastery & & -0.692 & 0.000 \\
Personal Growth & & -0.559 & 0.000 \\
Positive Relations with Others & & -0.700 & 0.000 \\
Purpose in Life & -0.287 & 0.000 & \\
Self-Acceptance & -0.448 & 0.000 & \\
\hline
\end{tabular}

Table 5 Correlational analyses between PWB variable and teacher stress dimensions

\begin{tabular}{ccc}
\hline & \multicolumn{2}{c}{ Psychological Well-being Variable } \\
& $\mathbf{r}$ & $\mathbf{p}$ \\
\hline Role Ambiguity & -0.360 & 0.000 \\
Role Overload & -0.452 & 0.000 \\
Role Conflict & -0.605 & 0.000 \\
Nonparticipation & -0.361 & 0.000 \\
Role Preparedness & -0.328 & 0.000 \\
School Stress & -0.457 & 0.000 \\
Job Satisfaction & -0.357 & 0.000 \\
Management Style & -0.263 & 0.000 \\
Life Satisfaction & -0.565 & 0.000 \\
Task Stress & -0.761 & 0.000 \\
Supervisory Support & -0.386 & 0.000 \\
Peer Support & -0.227 & 0.000 \\
Illness Symptoms & -0.566 & 0.000 \\
\hline
\end{tabular}

Table 4 and Table 5 present the intercorrelation between variables and each dimension. It shows that teacher stress has a negative relation to all dimensions of psychological well-being and vice versa. This means the higher stress experienced by the teachers will make them feel uneasy to themselves, not able to build and maintain relationship with other people, not able to control their surroundings, and lack of purpose in life. 
Table 6 Comparison between age groups - One way ANOVA between subject designs

\begin{tabular}{|c|c|c|c|}
\hline Variable & Age Groups & Mean & p \\
\hline \multirow{3}{*}{ Teacher Stress } & $20-29$ & 2.1955 & \multirow{3}{*}{0.043} \\
\cline { 2 - 3 } & $30-39$ & 2.1707 & \multirow{2}{*}{0} \\
\cline { 2 - 3 } & $40-49$ & 1.9182 \\
\cline { 2 - 3 } & $50-59$ & 1.9758 & \\
\hline
\end{tabular}

Table 6 presents teacher stress means comparison between various age groups: age 20-29, age 30-39, age 40-49, and age 50-59. One-way ANOVA between subject's design was used to compare means in teacher stress variable. It says that there is a significance difference in teacher stress between age 20-29, age 30-39, age 40-49, and age 50-59. Age 20-29 was found to experience more stress than any other age groups. It significantly differs in job satisfaction, life satisfaction, and task stress dimensions. That means participants from age 20 to 29 tend to have low satisfaction level towards their job and life and also more prone to stress caused by problems related to their teaching setting and activities.

Table 7 Comparison between age groups - Kruskal-Wallis H-test

\begin{tabular}{|c|c|c|c|}
\hline Variable & Age Groups & Mean & p \\
\hline \multirow{3}{*}{ Psychological Well-being } & $20-29$ & 61.49 & \multirow{2}{*}{0.006} \\
\cline { 2 - 3 } & $30-39$ & 72.28 & \multirow{2}{*}{0.06 .05} \\
\cline { 2 - 3 } & $40-49$ & 66.86 & \\
\cline { 2 - 3 } & $50-59$ & \multicolumn{2}{|c}{} \\
\hline
\end{tabular}

Table 7 presents psychological well-being mean score comparison between age 20-29, age 30-39, age 40-49, and age 50-59. This comparison used Kruskal Wallis H Test and shows that participants ranging from 40 to 49 years old have the highest level of psychological well-being compared to all age groups. It significantly differs in environmental mastery, personal growth, positive relations with others, and self-acceptance dimensions. That means participants from age 40 to 49 have a better ability to control their situation, maintain their growth and positive relationship with others, also better at accepting themselves in any conditions.

\section{CONCLUSIONS}

This research proved that there is a significant and negative relation between teacher stress and psychological well-being in junior high school teachers during this distance learning situation. Participants in this research reported to have a low score of teacher stress. In the other hand, they score pretty high on psychological well-being.

Even though the mean scores are low, teachers still need attention during this situation because there are still some possibilities that some teachers experience teacher stress because some participants reported to have high score on some dimensions.

This research have several limitations. Researcher haven't included teacher job status in the demographic information forms. Full-timer teachers and part-time teachers might have differ in stress levels and/or psychological well-being levels, further research is needed. In the next research, psychosocial or other form of wellbeing can be considered to be explored more. Also, using different measurement for teacher stress in which have lesser number of items is recommended, but still, it has to be representative to the teacher stress terms. Further research may want the data to be more homogeneous to achieve a result that is more representative and specifically aimed at certain groups of teachers.

\section{ACKNOWLEDGMENT}

This work was supported by Faculty of Psychology, Universitas Tarumanagara, Jakarta.

\section{REFERENCES}

[1] A. B. Santosa. "Potret pendidikan di tahun pandemi: Dampak COVID-19 terhadap disparitas pendidikan di Indonesia." Centre for strategic and international studies. https://www.csis.or.id/publications/potret-pendidikan-ditahun-pandemi-dampak-covid-19-terhadap-disparitaspendidikan-di-indonesia (Accessed in September 30, 2020)

[2] University of Missouri-Columbia. "Nearly all middle school teachers are highly stressed: Education experts suggest findings indicate a need to reduce burden of teaching" ScienceDaily. www.sciencedaily.com/releases/ 2020/01/200127134722.htm (Accessed in September 30, 2020)

[3] R. J. Mykletun, "Teacher stress: Perceived and objective sources, and quality of life," Scandinavian Journal of Educational Research, 28, 1, 17-45, Mar 1984, doi: 10.1080/0031383840280103 
[4] E. Scott. "What is stress?" VeryWellMind. https://www.verywellmind.com/stress-and-health-3145086 (Accessed in September 13, 2020)

[5] F. A. Huppert, "Psychological well-being: Evidence regarding its causes and consequences," Applied Psychology: Health and Well-Being, 1, 137-164, Jun 2009 https://doi.org/10.1111/j.1758-0854.2009.01008.x

[6] E. L. Deci and R. M. Ryan, "Hedonia, eudaimonia, and well-being: An introduction," Journal of Happiness, 9, 111, Jan 2008, DOI: 10.1007/s10902-006-9018-1

[7] E. Diener, "Subjective well-being: The science of happiness and a proposal for a national index," American Psychologist, 55, 34-43, Jan 2000, https://doi.org/10.1037/ 0003-066X.55.1.34

[8] C. D. Ryff, "Happiness is everything, or is it? Explorations on the meaning of psychological well-being," Journal of Personality and Social Psychology, 57, 6, 10691081, Dec 1989, https://doi.org/10.1037/0022-3514.57. 6.1069

[9] C. D. Ryff, "Psychological well-being in adult life," Current Directions in Psychological Science, 4, 4, 99-104, 1995, DOI: 10.1111/1467-8721.ep10772395

[10] F. McCallum and D. Price, "Well teachers, well students," Journal of Student Well-being, 4, 1, 19-34, Nov 2010, DOI: 10.21913/JSW.v4i1.599

[11] N. Embse and A. Mankin, "Changes in teacher stress and Well-being throughout the academic year," Journal of Applied School Psychology, 1-20, Aug 2020, DOI: 10.1080/15377903.2020.1804031

[12] S. Zaki, "Psychological well-being: Teachers need to enhance in teaching," International Education \& Research Journal, 2, 7, 27-29, Jul 2016, https://www.academia.edu/ 27258819/Psychological_well_being_teachers_need_to_e nhance_in_teaching

[13] H. Selye, "Implications of stress concept," New York State Journal of Medicine, 75, 12, 2139-2145, Oct 1975, https://psycnet.apa.org/record/1976-28063-001

[14] R. S. Lazarus and S. Folkman, Stress, Appraisal, and Coping, New York, USA: Springer, 1984. [Online]. Available: https://books.google.co.id/books?hl=en\&lr=\&id =i-ySQQuUpr8C\&oi=fnd\&pg=PR5\&dq=lazarus+stress+ appraisal+and+coping\&ots=DgDOmwekSd\&sig $=W 558 \mathrm{~m}$ zRT1_3oq3vq8Xd92_7xe78\&redir_esc $=y \# v=o n e p a g e \& q$ $=$ lazarus $\% 20$ stress $\% 20$ appraisal $\% 20$ and $\% 20$ coping $\& \mathrm{f}=$ fal se

[15] C. Kyriacou, "Teacher Stress: Directions for future research." Educational Review, 53, 1, 27-35, Feb 2001, doi:10.1080/00131910120033628
[16] L. S. Pettegrew and G. E. Wolf, "Validating measures of teacher stress," American Educational Research Journal, 19, 3, 373-396, 1982, DOI: 10.3102/ 00028312019003373

[17] J. C. de Souza, I. C. de Sousa, A. S. Belísio, and de C. V. M. Azevedo, "Sleep habits, daytime sleepiness and sleep quality of high school teachers," Psychology \& Neuroscience, 2, 257-263, Dec 2012 http://dx.doi.org/ 10.3922/j.psns.2012.2.17

[18] World Health Organization. "Mental health and work: Impact, issues, and good practices." World Health Organization \& International Labor Organization. https://www.who.int/mental_health/media/en/712.pdf (Accessed in September 20, 2020)

[19] J. S. Yoon, "Teacher characteristics as predictors of teacher-student relationships: Stress, negative affect, and self-efficacy," Social Behavior and Personality: An International Journal, 30, 5, 485-493, Jan 2002, DOI: 10.2224/sbp.2002.30.5.485 